\title{
A COMPARISON OF ACADEMIC PERFORMANCE MEASURES OF HSTA PARTICIPANTS WITH NON-HSTA PARTICIPANTS: IS IT POS- SIBLE TO NARROW THE AFRICAN AMERICAN-WHITE ACHIEVE- MENT GAP?
}

\author{
Sherron Benson McKendall ${ }^{1}$, Alan McKendall ${ }^{2}$, and Ann Chester $^{1}$
}

${ }^{1}$ Health Sciences and Technology Academy, West Virginia University, Morgantown, WV ${ }^{2}$ Department of Industrial and Management Systems Engineering, West Virginia University, Morgantown, WV

Keywords: Out-of-School Time (OST) Enrichment Programs, Standardized Test Scores, College GPA, Factorial ANOVA, African American-White Achievement Gap, Diverse Perspectives.

Publication Date: December 10, 2019

DOI: https://doi.org/10.15695/jstem/v2i1.20

\begin{abstract}
Historically, African American and other underserved students encounter academic challenges in pursuit of a college degree - one of which is their performance on standardized tests. This paper analyzes College Grade Point Averages (CGPAs), ACT Composite (ACTC), and SAT Total (SATT) scores of students who participated in the Health Sciences and Technology Academy (HSTA), an out-of-school-time (OST) program, and Non-HSTA (NHSTA) students attending West Virginia University. Traditionally, OST programs provide academic enrichment to underserved youth to increase their chances for post-secondary entry and success. Two-Way Factorial ANOVA determined if HSTA participants performed better on academic measures than their NHSTA counterparts. The ANOVAs showed statistically significant differences based on Status (HSTA/NHSTA) and Race (African American/White) on the SATT and ACTC. Although not statistically significant, there are favorable outcomes on the CGPA for African American HSTA students comparable to their Non-HSTA counterparts.
\end{abstract}

\section{INTRODUCTION}

During the mid-1800s Horace Mann made an effort to address the social inequalities in the Boston Public Schools by introducing the first concepts of standardized testingthe Common Exam. Mann's intent was to acquire unbiased valuable information with the purpose of restructuring a system in which all students would have access to an equitable education. As he so eloquently wrote,

Education, then, beyond all other devices of human origin, is the great equalizer of the conditions of menthe balance-wheel of the social machinery... it gives each man the independence and the means, by which he can resist the selfishness of other men . . . it prevents being poor (Mann, 1848).

What was originally a tool for addressing educational inequalities has developed into, over the centuries, a mech- anism for categorizing individual students as intellectual elites, standards, or dregs of society. The modern forms of the Common Exam, the Scholastic Assessment Test (SAT) and the ACT, are now academic measurements utilized as indicators of mental aptitude/abilities and are oftentimes a determinant of college admission in the United States (Borman et al., 2003; Rothstein, 2010). However, underserved (e.g., African American, financially disadvantaged, first generation college) students may not perform well on these entrance exams, which may serve as obstacles to post-secondary pursuit (Cates and Schaefle, 2011; Jencks and Phillips, 1998; Walpole et al., 2005). Standardized tests are a highly studied indicator of the achievement gap between served and underserved youth, and there is a definitive disparity in these scores that occur along the lines of race/ethnicity, gender, family, and household income (College Board, 2014; National Center for Education Statistics, 2012). 
Addressing the Achievement Gap in Standardized Testing. The U.S. has implemented numerous policies and programs to address the achievement gap beginning with the 1954 Brown vs. Board of Education Act stipulating that the "doctrine of separate but equal ... had no place in the field of education" (National Center for Public Policy Research, 2016). Ten years after this landmark decision, in response to Section 402 of the Civil Rights act of 1964, James Coleman, a then prominent sociologist, spearheaded the release of the governmental report titled "The Equality of Educational Opportunity." This report was the first national attempt to assess the "lack of availability of educational opportunities for individuals by reason of race, color, religion or national origin in public educational institutions at all levels in the United States..." (Coleman et al., 1966, p. iii). On the precipice of the Coleman report, the government responded by implementing The Elementary and Secondary Education Act of 1965, requiring school districts to integrate in order to receive federal funding in hopes that integration would enhance the learning of underserved students (Pitre and Pitre, 2009). Over half a century has passed since the "Coleman Report" and the "Education Act of 1965," and our nation continues to grapple with the question of how to reduce the achievement gap between underserved students, specifically African Americans, and their counterparts.

Evidence-Based Reform: Addressing Educational Disparities. The use of objective evidence to guide educational reform in our nation's schools has grown increasingly common. Educators and researchers employ a variety of methods to evaluate the efficacy of in-school programming, inform the design of academic offerings, hold educators accountable for results, and so on. However, standardized tests are the gold standard for measurement. Despite criticism of the role standardized testing plays in America's education system today-e.g., structure and content may not be accessible to all students and educators are now "teaching to the test"these test scores are used to determine school efficacy, identify students for college-track versus vocational coursework, and finally acceptance/rejection for college admittance.

As an analytical tool for addressing educational disparities, evidenced-based reform - the use of rigorous research to inform the practice of education and educational policyis a valuable pathway toward improving U.S. educational systems; however, the experimental designs must be based on sound methodology (Cooper, 2013; Haney, 1977; Kennedy, 1978; Slavin, 2005; Wandersman et al., 2016).

Evidence-based reform largely focuses on time in school systems; however, OST programs can apply this concept. To help combat the challenges encountered by at-risk students, OST programs must strive to cultivate academic achievement in measurable ways by providing supplemental educational resources that may directly affect measured achievement de- liverables such as grades and standardized test scores. Implementing evidenced-based evaluations in the OST realm could proceed as such: assessing student responses regarding preferred modes of learning (e.g., listening to the teacher talk in front of the class vs. completing hands-on projects) relative to how well they design and implement research projects or documenting parental perceptions of an OST program effectiveness in regard to increasing performance in the classroom. A more rigorous design would include random designed experimental-control studies examining predictors of academic success that utilize both cognitive and non-cognitive factors. This research could enlighten OST directors, educators, and policymakers as to best practices for creating or redesigning program components. As such, an important question for educators and policy makers to consider is "Can OST/science, technology, engineering, and mathematics (STEM) enrichment programs increase academic achievement outcomes, namely standardized test scores and CGPA for underserved students?" Another important question is "What are possible programmatic elements that can help to address the racial/social stigmas that underserved students encounter so that they can reach their highest level of academic potential?'”

The Health Sciences and Technology Academy Model. For 25 years, the Health Sciences and Technology Academy (HSTA) has served as an academic enrichment program for African American, first generation college, financially disadvantaged and rural students of West Virginia. The program provides critical academic and social skills to assist students as they progress through the educational pipeline from high school to college. HSTA's mission is to increase the number of African American and other underserved students in West Virginia who pursue degrees in health sciences/STEM majors, thereby increasing the number of health practitioners and advocates in medically underserved communities as well as STEM graduates. As a grassroots, community based organization in partnership with institutions of higher learning, HSTA provides an academic experience to assist students in reaching their highest potential and realizing their dreams of academic and life success. In 2013, HSTA designed a logic model detailing the program's goals and strategies as well as the short and long-term outcomes for intended participants (See Figure 1).

Organizational Strategies: Addressing Racial and Societal Barriers. Steele, Spencer, and Aronson (2002) provide two primary organizational strategies (relational and contextual) for lessening the effects of stereotype and social identity threats which closely align with the HSTA model. Relational strategies are friendships, expert tutors, mentoring and ability affirmation, and success-affirming role models and mentors. HSTA provides countless opportuni- 


\section{HSTA Logic Model}

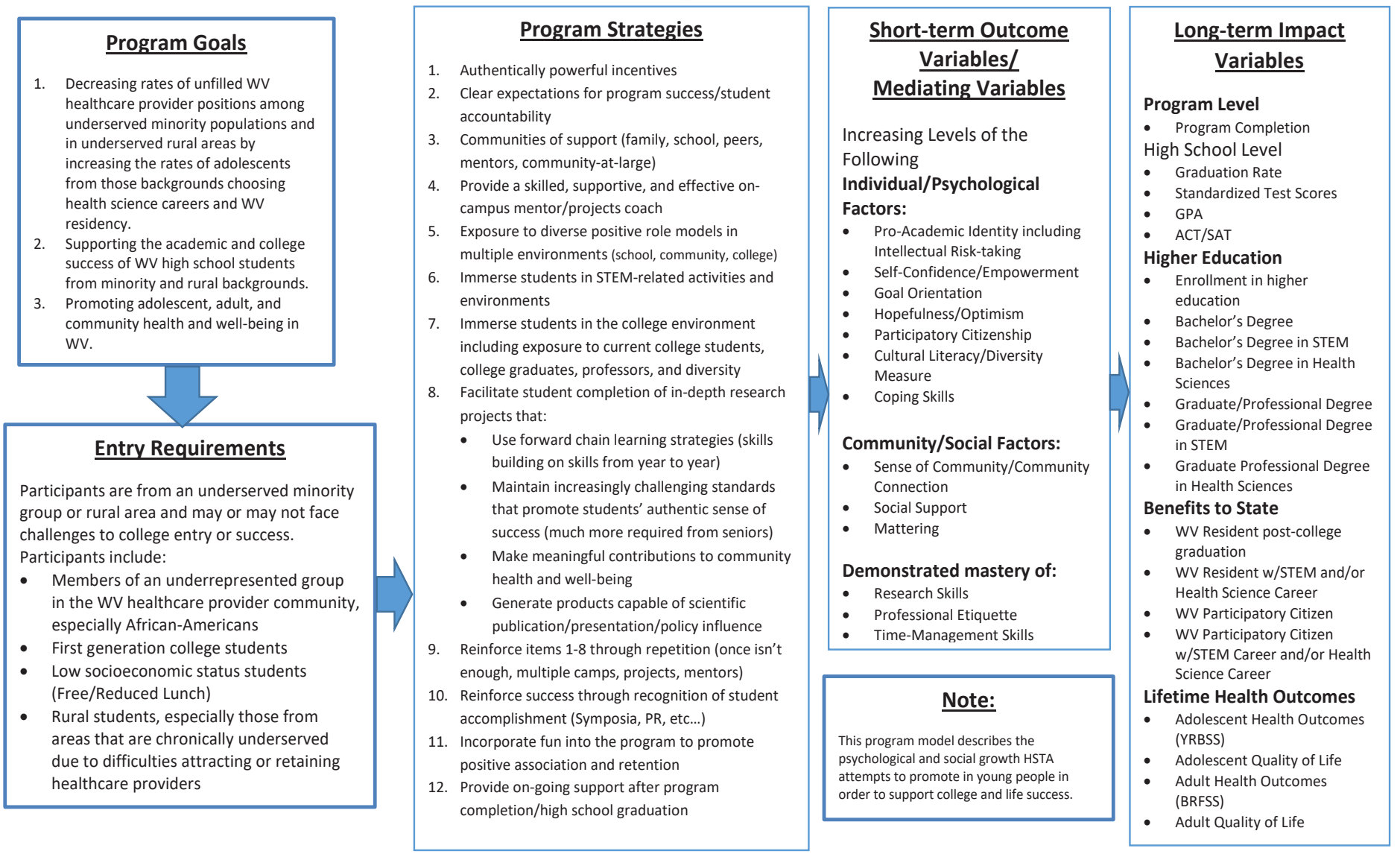

Figure 1. HSTA Logic Model of Program Goals, Entry Requirements, Strategies, and Impact Variables.

ties for students to build friendships and encounter success affirming mentors/role models by building communities of support exposing them to diverse positive role models at school, in their communities, and from university campuses. Participants also receive affirmation of their success by recognition of their accomplishments through HSTA events or the media. HSTA trained teachers provide expert tutoring which guides and helps participants in completing a yearly in-depth research project designed to promote skill building and maintain increasingly challenging standards as they progress through the program with the goal of promoting an authentic sense of success in the participants. According to Steele et al., an organization's settings represent contextual strategies whereby there is value in racial and social identity, a diverse philosophy and minority presence exist, and there is a presence of procedural justice and minority trust. As a program designed to promote the success of underserved populations, the HSTA model embraces relational and contextual organizational strategies.

Regardless of race, gender, or socio-economic status, HSTA encourages students with the belief that they can accomplish their aspirations with hard work and persever- ance. Students also encounter a minority presence given that they interact with individuals from backgrounds similar to their own who have overcome the odds by earning higher degrees and having successful careers (Hornbeck, 2017). As a grassroots organization, a panel of local community individuals (e.g., parents, business owners, former HSTA participants, medical practitioners, etc.) set and guide HSTA policies and procedures. Fellow community members who have their best interest in mind govern HSTA students and; as a result, they experience an atmosphere of procedural justice and minority trust. Thus, all students, with no exceptions, are held accountable (e.g., probation or possible expulsion) if they do not meet the program standards. By modeling these relational and contextual strategies, HSTA creates and promotes an environment dampening the effects of stereotype threat and social identity stigma, which could otherwise impede participants' academic success. HSTA participants receive affirmations that they belong, that they can succeed, and that they have a social support system through HSTA to assist them in their success through college and beyond (SmithBranch et al., 2018). 
Table 1: Student Demographics by Status and Race

\begin{tabular}{llll}
\hline & HSTA & NHSTA & Total \\
\hline Blacks/African Americans & $88(2.72 \%)$ & $3143(97.28 \%)$ & 3231 \\
Whites/Caucasians & $218(0.30 \%)$ & $72136(99.70 \%)$ & 72354 \\
Total & 306 & 75279 & 75585 \\
\hline Notes: Percentages in parentheses are computed within rows.
\end{tabular}

Notes: Percentages in parentheses are computed within rows.

Purpose of the current study. This study seeks to determine if HSTA participants have higher overall academic performance measures (i.e., CGPA, ACTC and SATT scores) than Non-HSTA participants attending college by considering the following questions:

(1) Do Status (i.e., HSTA and Non-HSTA) and Race (i.e., Black/African American and White/Caucasian) have an effect on the academic performance of the populations?

(2) Do Status and Race interact to effect the academic performance measures?

There is minimal research that examines whether participants/graduates of pre-college enrichment programs have been better prepared to pursue 4-year degrees compared to those who have not. The purpose of this study is to determine if students who receive the HSTA intervention are more likely to attain higher college entrance standardized test scores and CGPAs because they receive pre-college services that provide them with the foundation to reach their academic potential. In a previous study, HSTA's high school students showed a competitive edge in performance over their Non-HSTA counterparts on state-mandated standardized tests (Smith-Branch et al., 2018). Essentially, HSTA makes a difference in the lives of students in both the development of their skills and knowledge as well as their access to higher education (McKendall et al., 2014). This study is an analysis of HSTA's impact on participants' educational success in high school and in college.

\section{METHODS}

We utilized archival internal data from the West Virginia University (WVU) registrar's office for students enrolled during the 1997-98 through 2011-12 academic calendar years. The data set includes demographics (i.e., race), high school Grade Point Average (HSGPA), ACTC, SATT scores, enrollment status, and cumulative CGPAs for all undergraduate students. In order to perform the analyses, a high school grade point average (HSGPA) of 2.48 or above was required, as this was the lowest HSGPA of HSTA students. In addition, West Virginia residency was required for the NHSTA cohort. We used the statistical software SAS 9.4 for Windows during the data analysis process. The final data set comprised 306 HSTA and 75,279 NHSTA students totaling 75,585 participants. The participants' demographics are 3,231 African American and 72,354 White students. Table 1 provides detailed demographics by Status and Race.

Factorial Analysis. A complete factor analysis, which is advantageous in examining the main effects of two or more independent variables simultaneously as well as interactions between the variables, was used in the data analysis (Collins et al., 2009; Lavrakas, 2008). In general, factorial designs are most efficient for this type of experiment given that an examination of each complete trial/replication of the experiment and all possible combinations of the levels of the factors takes place.

\section{RESULTS}

We conducted analyses on each of the dependent variables (i.e., ACTC, SATT, and CGPA) and the two main factors (Status and Race) to determine statistically significant differences. Table 2 provides the GLM models for each of the dependent variables. The models show evidence that the means of the dependent variables for Status and Race are different. In Table 3, the Type III SS is presented for each of the models displaying significance levels of the main effects and their interaction.

Analyses of the GLM models for the mean ACTC and SATT scores show an effect on Status (HSTA/NHSTA) and Race (African American/White). Given the $p$-values, there are significant differences between these groups; however, the interaction terms show no differences. Although the overall GLM model for CGPA show a significant difference, the Type III SS does not show significant differences for Status, Race or the interaction. However, when the CGPA model was repeated without the interaction term, it showed a significant difference for Race $F(1,72,891)=26.28, p=<.0001)$. The mean difference in CGPA for African American $(n=3019)$ compared to White ( $\mathrm{n}=69803)$ students was 2.54 vs. 2.92 and for the HSTA African American $(n=88)$ compared to NHSTA African American ( $\mathrm{n}=3003)$ students, it was 2.67 vs. 2.40 .

Table 2. GLM models by Dependent Variables for Status and Race (All Participants)

\begin{tabular}{lrrrrrrrrrr}
\hline Model & CT & \multicolumn{1}{c}{$\bar{X}$} & df & \multicolumn{1}{c}{ SS } & MS & COV & $R^{2}$ & RMSE & $F$ Value & Pr $>$ F \\
\hline ACTC & 37710 & 22.56 & 3 & 8808.67 & 2936.22 & 16.76 & .02 & 3.78 & 205.41 & $* *$ \\
SATT & 40229 & 1030.93 & 3 & 18233881.0 & 6077960.3 & 13.81 & .02 & 142.32 & 300.06 & $* *$ \\
CGPA & 72892 & 2.80 & 3 & 508.694 & 169.565 & 156.40 & .00 & 4.38 & 8.84 & $* *$ \\
\hline
\end{tabular}

Note: $C T=$ Corrected Total; $S S=$ Sum of Squares; $M S=$ Mean Squares; $R^{2}=R$-Square; RMSE = Root Mean Square Error; COV = Coefficient of Variation; significance level $=* * p<0.0001$ 
Table 3. GLM Procedure for ACTC, SATT and CGPA Scores

\begin{tabular}{llrrr}
\hline Source & DF & Type III SS & F Value & $\boldsymbol{P r}>\boldsymbol{F}$ \\
\hline ACTC & & & & \\
STATUS & 1 & 222.601704 & 15.57 & $<.0001$ \\
RACE & 1 & 1906.517238 & 133.38 & $<.0001$ \\
STATUS*RACE & 1 & 1.422347 & 0.10 & 0.7524 \\
SATT & & & & \\
STATUS & 1 & 360334.0649 & 17.79 & $<.0001$ \\
RACE & 1 & 742698.6441 & 36.67 & $<.0001$ \\
STATUS*RACE & 1 & 5522.6243 & 5522.6243 & 0.6016 \\
CGPA & & & & \\
STATUS & 1 & 13.60082884 & 0.71 & 0.3998 \\
RACE & 1 & 36.05460851 & 1.88 & 0.1704 \\
STATUS*RACE & 1 & 0.24803942 & 0.01 & 0.9095 \\
\hline
\end{tabular}

The ACTC and SATT models shows that there is a difference between HSTA and NHSTA students as well as between African American and White students; however, the interaction terms in each of these models illustrates that the effects of HSTA do not differ for African American and White students in terms of ACTC and SATT scores. Comparatively, the CGPA model demonstrates no difference for Status (HSTA vs. NHSTA), Race (African Americans vs. Whites) or the interaction between Status and Race. It is determined that the effects of HSTA participation are evident in the first two models of ACTC and SATT for the main effects; however,
HSTA participation has no statistically significant difference on the CGPA of HSTA compared to NHSTA students.

In order to determine where the differences are in the mean scores across the groups for the ACTC and SATT scores, we used Tukey's Honestly Significant Difference (HSD) adjustment for multiple comparisons. The Tukey-Kramer procedure shows the difference in the mean scores between HSTA and NHSTA students on the ACTC and SATT is -0.98 and -67.21, respectively (See Table 4). Analyses of the variable Race also produced statistically significant differences in the ACTC and SATT LS-Means between African American and White students (See Table 5). The simultaneous 95\% CL between LS-Mean(i) and LS-Mean(j) for each of the variables is also presented in Tables 4 and 5.

Tables 6 and 7 also display LS-Means and the 95\% Confidence Limits for Status by Race for ACTC and SATT, respectively. The multiple comparisons show significant differences for all of the interactions for ACTC scores. It is also important to note that the NHSTAAfrican American students' ACTC score is significantly different from the HSTA African American students $(p=0.03$ ). The 1.89 difference between the means for HB and NHW students is lower than the difference for NHB and NHW of -2.79 . The largest difference in ACTC LS-Means was between HW and NHB (-3.85) compared to a -2.95 difference between HB and HW scores.

SATT LS-Means scores and significance levels represented in Table 8 for the interaction between the main effects

Table 4. LS-Means for Dependent Variables by Status Adjustment for Multiple Comparisons: HSD

\begin{tabular}{|c|c|c|c|c|c|c|c|c|}
\hline & \multirow[b]{2}{*}{ LS-Mean } & \multirow[b]{2}{*}{$\begin{array}{l}\text { Standard } \\
\text { Error }\end{array}$} & \multirow[b]{2}{*}{$t$-value } & \multicolumn{2}{|c|}{$95 \% \mathrm{CL}$} & \multirow[b]{2}{*}{$\begin{array}{c}\text { Diff. Between } \\
\text { Means }\end{array}$} & \multicolumn{2}{|c|}{ Simultaneous $95 \% \mathrm{CL}$} \\
\hline & & & & Lower & Upper & & LSMean (i) & LSMean (j) \\
\hline \multicolumn{9}{|l|}{ ACTC } \\
\hline HSTA & $22.23^{* *}$ & 0.24 & -3.95 & 21.76 & 22.70 & -0.98 & -1.47 & 0.49 \\
\hline NHSTA & 21.25 & 0.06 & & 21.14 & 21.36 & & & \\
\hline \multicolumn{9}{|l|}{ SATT } \\
\hline HSTA & $1050.16^{* *}$ & 15.84 & -4.22 & 1019.10 & 1081.19 & -67.21 & -98.44 & -35.98 \\
\hline NHSTA & 982.94 & 1.76 & & 979.49 & 986.38 & & & \\
\hline
\end{tabular}

Note: $* * p<0.0001$

Table 5. LS-Means for Dependent Variables by Race Adjustment for Multiple Comparisons: HSD

\begin{tabular}{|c|c|c|c|c|c|c|c|c|}
\hline & \multirow[b]{2}{*}{ LS-Mean } & \multirow[b]{2}{*}{$\begin{array}{l}\text { Standard } \\
\text { Error }\end{array}$} & \multirow[b]{2}{*}{ t-value } & \multicolumn{2}{|c|}{$95 \% \mathrm{CL}$} & \multirow[b]{2}{*}{$\begin{array}{c}\text { Diff. Between } \\
\text { Means }\end{array}$} & \multicolumn{2}{|c|}{ Simultaneous $95 \%$ CL } \\
\hline & & & & Lower & Upper & & LSMean (i) & LSMean (j) \\
\hline \multicolumn{9}{|c|}{ ACTC } \\
\hline Black & $20.31^{* *}$ & 0.21 & -11.55 & 19.89 & 20.72 & -2.87 & -3.35 & -2.38 \\
\hline White & 23.17 & 0.13 & & 22.92 & 23.43 & & & \\
\hline \multicolumn{9}{|l|}{ SATT } \\
\hline Black & $968.30^{* *}$ & 12.50 & -6.06 & 943.78 & 992.81 & -96.49 & -127.72 & -65.26 \\
\hline White & 1064.79 & 9.87 & & 1045.43 & 1084.14 & & & \\
\hline
\end{tabular}

Note: $* * p<0.0001$ 
Table 6. LS-Means for ACTC by Status*Race with 95\% Confidence Limits and Adjustment for Multiple Comparisons: HSD Pr > |t| for H0: LS$\operatorname{Mean}(i)=\operatorname{LS}-\operatorname{Mean}(j)$

\begin{tabular}{|c|c|c|c|c|c|c|c|c|c|c|}
\hline & \multirow[b]{2}{*}{ LS-Mean } & \multirow[b]{2}{*}{$\begin{array}{c}\text { Standard } \\
\text { Error }\end{array}$} & \multicolumn{2}{|c|}{$95 \% \mathrm{CL}$} & \multirow[b]{2}{*}{$\mathrm{i}$} & \multirow[b]{2}{*}{$\mathrm{j}$} & \multirow[b]{2}{*}{ t-value } & \multirow[b]{2}{*}{$\begin{array}{c}\text { Diff. Between } \\
\text { Means }\end{array}$} & \multicolumn{2}{|c|}{ Simultaneous $95 \%$ CL } \\
\hline & & & Lower & Upper & & & & & LSMean(i) & LSMean(j) \\
\hline NHB & 19.85 & 0.11 & 19.63 & 20.08 & NHB & $\mathrm{NHW}^{* *}$ & 24.03 & -2.79 & -3.09 & -2.49 \\
\hline NHW & 22.64 & 0.02 & 22.60 & 22.68 & NHB & $\mathrm{HB}^{*}$ & 2.13 & -0.91 & -1.99 & 0.19 \\
\hline HB & 20.76 & 0.41 & 19.96 & 21.56 & NHB & $\mathrm{HW}^{* *}$ & 13.61 & -3.85 & -4.57 & -3.12 \\
\hline \multirow[t]{3}{*}{ HW } & 23.70 & 0.26 & 23.19 & 24.21 & NHW & $\mathrm{HB}^{* *}$ & 4.62 & 1.89 & 0.84 & 2.94 \\
\hline & & & & & NHW & $\mathrm{HW}^{* *}$ & 4.08 & -1.06 & -1.72 & -0.39 \\
\hline & & & & & HB & $\mathrm{HW}^{* *}$ & 6.10 & -2.95 & -4.19 & -1.71 \\
\hline
\end{tabular}

$* p<.05, * * p<0.0001$

$N H B=$ Non-HSTA Black; NHW=Non-HSTA White; HB=HSTA Black; HW=HSTA White

Table 7. LS-Means for SATT by Status*Race with 95\% Confidence Limits and Adjustment for Multiple Comparisons: HSD Pr > |t $\mid$ for H0: LS$\operatorname{Mean}(i)=\operatorname{LS}-\operatorname{Mean}(j)$

\begin{tabular}{|c|c|c|c|c|c|c|c|c|c|c|}
\hline & \multirow[b]{2}{*}{ LS-Mean } & \multirow[b]{2}{*}{ Standard Error } & \multicolumn{2}{|c|}{$95 \% \mathrm{CL}$} & \multirow[b]{2}{*}{$\mathrm{i}$} & \multirow[b]{2}{*}{$\mathrm{j}$} & \multirow[b]{2}{*}{ t-value } & \multirow[b]{2}{*}{ Diff. Between Means } & \multicolumn{2}{|c|}{ Simultaneous $95 \% \mathrm{CL}$} \\
\hline & & & Lower & Upper & & & & & LSMean(i) & LSMean(j) \\
\hline NHB & 930.53 & 3.44 & 923.79 & 937.27 & NHB & $\mathrm{NHW}^{* *}$ & 29.81 & -104.81 & -113.84 & -95.78 \\
\hline NHW & 1035.34 & 0.73 & 1033.92 & 1036.76 & NHB & $\mathrm{HB}^{* *}$ & 3.02 & -75.53 & -139.79 & -11.27 \\
\hline $\mathrm{HB}$ & 1006.06 & 24.76 & 957.50 & 1054.62 & NHB & $\mathrm{HW}^{* *}$ & 8.17 & -163.70 & -215.17 & -112.23 \\
\hline \multirow[t]{3}{*}{ HW } & 1094.23 & 19.74 & 1055.55 & 1132.92 & NHW & $\mathrm{HB}^{(\mathrm{ns})}$ & 1.18 & 29.28 & -34.40 & 92.96 \\
\hline & & & & & NHW & $\mathrm{HW}^{* *}$ & 2.98 & -58.89 & -109.63 & -8.15 \\
\hline & & & & & HB & $\mathrm{HW}^{* *}$ & 2.78 & -104.81 & -113.84 & -95.78 \\
\hline
\end{tabular}

Note: $N H B=$ Non-HSTA Black; NHW=Non-HSTA White; HB=HSTA Black; HW=HSTA White.

${ }^{*} p<.05,{ }^{* *} p<0.0001, n s=$ not significant; $p$-value between $N H W$ and $H B$ is 0.238 .

showed that HSTA African American students' scores were significantly different from their Non-HSTA counterparts (1006.06 vs. 930.53, $p=0.014$ ). The results also revealed that HSTA African American students' SATT scores were not significantly different from the Non-HSTA White population $(p=0.24)$. Nevertheless, the point difference between the HB and NHW SATT was the least for all of the comparisons (29.28). Comparably, HSTA White students also performed better on the SATT score than their Non-HSTA counterparts (1094.23 vs. 1035.34, $p=0.003)$. The greatest difference in the LS-Mean scores is between HW and NHB (-163.70).

As with all studies, we recognize that there are limitations to this study. One might argue that there is a selection bias into the program, which brings into question the validity of this study. We acknowledge that there is a possibility of selection bias; however, this study provides a controlled evaluation (Winkleby et al., 2013) on a matched cohort study of HSTA and non-HSTA high school participants to determine if the outcomes are program versus selection effect (SmithBranch et al., 2018). In the past several years, randomized controlled trials (RCTs) have become increasingly popular in the education field (Connolly et al., 2018; Deaton and Cartwright, 2017). The HSTA selection process requires that potential HSTA participants must adhere to specific criteria (e.g., 2.5 GPA and have no disciplinary problems) and are required to write an essay discussing why they would want to participate in the HSTA program. The HSTA local governing boards; oftentimes, utilize these essays as a final factor to determine admittance. Thus, to conduct a true RCT would require restructuring HSTA's process in student selection. Although this is not a RCT, we do believe that this study provides some insight into HSTA's role in possibly narrowing the educational gap for underserved students. Another possible limitation is that HSTA participants are required to have a 2.5 high school GPA to enter the program and must successfully graduate with a 3.0 high school GPA, which may bring into question the validity of this study (Smith-Branch, et al., 2018). In order to address the issue of selection bias, we only included NHSTA students with comparable high school GPAs to their HSTA counterparts. An important consideration is that the impetus for programs such as HSTA is to provide the necessary academic enrichment; thereby, germinating the seeds for growth and maturity in academia and beyond; hence, the significantly higher test scores of the HSTA participants.

\section{DISCUSSION}

Evidenced based assessment of social programs affecting underserved groups is critically important given the political 
Table 8. LS-Means for SATT by Status*Race with 95\% Confidence Limits and Adjustment for Multiple Comparisons: HSD Pr > |t| for H0: LS$\operatorname{Mean}(i)=L S-M e a n(j)$

\begin{tabular}{|c|c|c|c|c|c|c|c|c|c|c|}
\hline & \multirow[b]{2}{*}{ LS-Mean } & \multirow[b]{2}{*}{$\begin{array}{c}\text { Standard } \\
\text { Error }\end{array}$} & \multicolumn{2}{|c|}{$95 \% \mathrm{CL}$} & \multirow[b]{2}{*}{$\mathrm{i}$} & \multirow[b]{2}{*}{$\mathrm{j}$} & \multirow[b]{2}{*}{ t-value } & \multirow[b]{2}{*}{$\begin{array}{c}\text { Diff. Between } \\
\text { Means }\end{array}$} & \multicolumn{2}{|c|}{ Simultaneous $95 \%$ CL } \\
\hline & & & Lower & Upper & & & & & LSMean(i) & LSMean(j) \\
\hline NHB & 930.53 & 3.44 & 923.79 & 937.27 & NHB & $\mathrm{NHW}^{* *}$ & 29.81 & -104.81 & -113.84 & -95.78 \\
\hline NHW & 1035.34 & 0.73 & 1033.92 & 1036.76 & NHB & $\mathrm{HB}^{* *}$ & 3.02 & -75.53 & -139.79 & -11.27 \\
\hline HB & 1006.06 & 24.76 & 957.50 & 1054.62 & NHB & $\mathrm{HW}^{* *}$ & 8.17 & -163.70 & -215.17 & -112.23 \\
\hline \multirow[t]{3}{*}{ HW } & 1094.23 & 19.74 & 1055.55 & 1132.92 & NHW & $\mathrm{HB}^{(\mathrm{ns})}$ & 1.18 & 29.28 & -34.40 & 92.96 \\
\hline & & & & & NHW & $\mathrm{HW}^{* *}$ & 2.98 & -58.89 & -109.63 & -8.15 \\
\hline & & & & & HB & $\mathrm{HW}^{* *}$ & 2.78 & -104.81 & -113.84 & -95.78 \\
\hline
\end{tabular}

Note: $N H B=$ Non-HSTA Black; NHW=Non-HSTA White; HB=HSTA Black; HW=HSTA White.

${ }^{*} p<.05, * * p<0.0001, n s=$ not significant; $p$-value between $N H W$ and $H B$ is 0.238 .

and social climate of the time. The U.S. has attempted to improve the educational disparities of underserved youth, particularly those who are African American and from impoverished backgrounds. Since the 1960's, the government has, in the pursuit of educational reform, implemented federal programs to assist students from disadvantaged backgrounds (Bisser, 2009; Haney, 1977; U.S. Department of Education, 2015). This call to action resulted in government and private agencies providing monetary rewards resulting in a plethora of educational programs aimed at increasing the number of underserved and underprivileged youth that attend college and purse specific career paths (e.g., STEM). Oftentimes, African American students are among the most poverty-stricken in the nation. According to the Condition of Education, "the percentage of students who attended high-poverty schools was highest for Hispanic students (45 percent), followed by African American students (44\%)... and White students (8 percent)" (National Center for Education Statistics, 2019). Despite the great need for such programs, the current administration has roughly suggested a $\$ 7.1$ billion dollar cut in education funding (Harris, 2019). Without federally funded educational programs that provide OST learning to enhance the learning experiences of underserved and underprivileged youth, many would not have the advantages of participating in programs such as HSTA. Accordingly, it is important for such educational programs to offer empirical studies examining the academic success of program participants to a comparative control group so that federal and local agencies can make informed, data driven decisions about the educational funding of such programs. To address this gap in the literature, this comparative study analysed the academic performance of HSTA (an OST/STEM enrichment program) participants relative to their Non-HSTA counterparts. As an academic and science intervention program, HSTA has become an important element to enhancing the academic performance of underserved students in West Virginia.

Over the course of four years, HSTA students encounter increasingly rigorous activities for building success as they matriculate through the program, which can culminate in taking a college-level course for academic credit prior to graduating high school. We consider it necessary to interweave academic rigor and social support in order to build relationships for success. However, academic rigor and social support are not enough; the curriculum needs to be relevant to the daily lives of students to aid in their retention and progression through the educational pipeline. Thus, HSTA diligently seeks to create positive educational environments and outcomes while attempting to dismantle the phenomena of stereotype threat performance for its participants (Steele et al., 2002). The result being that many go back into their communities and become sources of inspiration (Hornbeck, 2017). Thus, HSTA understands the importance of involving parents/family members in the participant's education and supports these efforts by coordinating parental meetings as well as encouraging parents to attend the annual science symposia in which students present the results of their research project to a panel of judges and their peers. HSTA believes parental/community involvement is crucial to understanding the social and cultural environment of our participants - a key component to meeting the needs of and engendering participants' success (McKendall et al., 2014). Although there is research showing that OST programs can have a tremendous impact on increasing pursuit of higher degrees in math and science, including Master's, $\mathrm{PhDs}$, and MDs (Carter et al., 2009; McKendall et al., 2014; Slovacek et al., 2011), there is still the need for more empirically based studies (Cooper, 2013; Slavin, 2005). Such studies could reveal the mechanisms through which these impacts occur. This study offers some evidence that HSTA aids in increasing standardized test scores, an integral component of college acceptance and a probable tool to measure college success. There are few studies comparing the standardized test scores of high school academic enrichment/STEM program participants to non-participants who have gone to college (Bausmith and France, 2012). There is also a need for comparative studies of CGPAs for academic enrichment 
program and non-program participants, and this study is the beginning of such endeavors.

Fostering Academic and Social Success. As an OST/ STEM enrichment program, HSTA participants receive the essential tools to improve upon the gatekeeper qualifications for students who historically exhibit lower standardized test scores. One of HSTA's primary goals is to prepare students to pursue post-secondary study and ultimately a career in Health Sciences/STEM related areas by creating community/academic partnerships, fostering parental/family involvement, and implementing core program components. The results of this study indicate that HSTA White participants show enhanced academic performance on standardized tests (McKendall et al., 2014; Smith-Branch et al., 2018). HSTA White students are surpassing their HSTA and non-HSTA counterparts on all of the academic measurements. It is evident that the HSTA intervention shows an effect for HSTA students on the ACTC and SATT scores. Although the results indicated that the HSTA intervention did not have a statistically significant difference in the CGPA, nor the interaction of Status and Race, it is important to note that the HSTA African American students are making some academic strides over their NHSTA counterparts. There is also the distinct possibility that the HSTA intervention could play a role in narrowing the academic gap between HSTA African Americans and NHSTA Whites. The HSTA African American participant population showed significant differences in their SATT scores from the Non-HSTA African American students, and they are doing slightly better in other areas. Furthermore, significant findings indicate that on some of the academic measurements (SATT and CGPA), HSTA African American students are not performing under par in comparison to Non-HSTA Whites.

Conclusion. This study employed metrics typically used to measure in school success and predictors of success in STEM fields to measure out-of-school-time programming, thus enhancing the body of empirical research with the purpose of validating the impact of academic/STEM enrichment programs. More importantly, we have shown that participation in an OST academic program, specifically HSTA, has an impact on enhancing the academic performance measures of African American, first generation to college, financially disadvantaged and rural students, revealing a best practice for improving STEM workforce development. As such, we believe that the HSTA strategies and interventions should be tested in other locations to determine possible nationwide implementation.

As an OST/STEM enrichment program, HSTA offers participants essential tools to improve upon gatekeeper qualifications - namely, standardized tests. This is a breakthrough for students who historically exhibit lower standardized test scores. HSTA students engage in challenging, diverse curriculum and build relationships with each other and with academic mentors. These experiences are shown to support students in being more effective test takers (McKendall et al., 2014; Afterschool Alliance, 2015; Hodges et al., 2017). As such, the effect of HSTA is twofold: students receive the support and educational resources essential to pursuing post-secondary study, and they go on to use this academic trajectory to attain vital careers in health sciences and other STEM areas (see Table 9). The goals set in place through HSTA are upheld by creating community-academic partnerships, fostering family involvement, and implementing the core program components of the HSTA club, the Science Symposia, and the Summer Institute. Thus, HSTA diligently seeks to create positive educational environments and outcomes while attempting to dismantle the phenomena of stereotype-threat performance (Steele et al., 2002). Essentially, these findings suggest that there is a positive correlation between program participation and higher standardized test scores, which exemplifies that HSTA, and potentially other OST/STEM enrichment programs, has the potential to affect the most important indicator of acceptance into post-secondary institutions. Further analyses through evidenced-based reform of other OST/STEM programs should be conducted in order to build upon the research substantiating the viabil-

Table 9. Health Care Professions Majors and Careers Chosen by Graduates of the West Virginia Health Sciences and Technology Academy, 1997-2019

\begin{tabular}{lcc}
\hline Major/Career* & $\begin{array}{c}\text { All } \\
\text { graduates }\end{array}$ & $\begin{array}{c}\text { African American } \\
\text { graduates }\end{array}$ \\
\hline $\begin{array}{l}\text { Medicine and pre-med (MD, DO) } \\
\text { Medicine, non-MD (physician }\end{array}$ & 32 & 21 \\
assistant, nurse practitioner, etc.) & 13 & 3 \\
$\begin{array}{l}\text { Dentistry } \\
\text { Nursing }\end{array}$ & 301 & 2 \\
$\begin{array}{l}\text { Pharmacy } \\
\text { Rehabilitative care (physical ther- } \\
\text { apy, occupational therapy, sports }\end{array}$ & 101 & 62 \\
medicine, etc.) & 44 & 14 \\
$\begin{array}{l}\text { Patient care, other (medical assis- } \\
\text { tant, respiratory therapy, etc.) }\end{array}$ & 156 & 36 \\
$\begin{array}{l}\text { Public and community health } \\
\text { Health care administration }\end{array}$ & 22 & 43 \\
$\begin{array}{l}\text { Mental health care } \\
\text { Radiology and related }\end{array}$ & 36 & 13 \\
$\begin{array}{l}\text { Allied health care (speech patholo- } \\
\text { gy, audiology, etc.) }\end{array}$ & 38 & 77 \\
$\begin{array}{l}\text { Research and pre-health care } \\
\text { professional (biomedical science, } \\
\text { biology, chemistry, etc.) }\end{array}$ & 177 & 4 \\
$\begin{array}{l}\text { STEM areas (Science, Technology, } \\
\text { Mathematics, Engineering) }\end{array}$ & 238 & 42 \\
*Health professions degrees include associates degrees and professional degrees. \\
\end{tabular}


ity of these programs in assisting underserved students to overcome educational barriers in pursuit of a higher standard of living.

\section{AUTHOR INFORMATION Corresponding Author}

Sherron Benson McKendall, Senior Research Associate. Health Sciences and Technology Academy. P.O. Box 9026 West Virginia University, Morgantown, WV, 26506-9026. (304) 293-1659. smckendall@hsc.wvu.edu.

\section{Author Contributions}

The manuscript was written through contributions of all authors. All authors have given approval to the final version of the manuscript.

\section{FUNDING SOURCE}

The authors wish to acknowledge grant support from WVCTSI award 5U54GM104942-03 from the NIH.

\section{ABBREVIATIONS}

ACTC: ACT Composite. CGPA: College Grade Point Average. GPA: Grade Point Average. HSGPA: High School Grade Point Average. HSTA: Health Sciences and Technology Academy. NHSTA: Non-HSTA. OST: Out-of-SchoolTime. RCT: Randomized Controlled Trial. SATT: SAT Total. STEM: Science, Technology, Engineering, and Mathematics. WVU: West Virginia University.

\section{REFERENCES}

Afterschool Alliance (2015). Evaluations backgrounder: A summary of formal evaluations of afterschool programs' impact on academics, behavior, safety and family life. Retrieved September 26, 2019, from http://afterschoolalliance.org/ documents/Evaluation_Backgrounder.pdf.

Bausmith, J. M., and France, M. (2012). The impact of GEAR UP on college readiness for students in low-income schools. Journal of Education for Students Placed at Risk (JESPAR), 17(4), 234-246.

Bisser, J. R. (2009). Voices of Trio students: promoting equity and social justice through the federal Trio programs. Saarbrücken, Germany: VDM Verlag Dr. Müller.

Borman G. D., Hewes G. M., Overman L. T., and Brown S. (2003) Comprehensive school reform and achievement: A meta-analysis. Review of Educational Research. 73(2), 125230 .
Carter, F. D., Mandell, M., and Maton, K. I. (2009). The influence of on-campus, academic year undergraduate research on STEM Ph.D. outcomes: Evidence from the Meyerhoff Scholarship Program. Educational Evaluation and Policy Analysis, 31(4), 441-462.

Cates, J. T., and Schaefle, S. E. (2011). The relationship between a college preparation program and at-risk students' college readiness. Journal of Latinos and Education, 10(4), 320 334. https://doi-org.www.libproxy.wvu.edu/10.1080/1534 8431.2011 .605683 .

Coleman, J. S., Campbell E. Q., Hobson C. J., McPartland J., Mood, A. M., Weinfeld, F. D., and York, R. L. 1966. Equality of Educational Opportunity. Washington, DC: U.S. Government Printing Office.

College Board. (2014). The 2014 SAT Report on College and Career Readiness. Retrieved February 25, 2019 from https:// www.collegeboard.org/program-results/2014/sat

Collins, L. M., Dziak, J. J., and Li, R. (2009). Design of experiments with multiple independent variables: a resource management perspective on complete and reduced factorial designs. Psychological Methods. 14(3), 202-224. doi: $10.1037 / \mathrm{a} 0015826$

Connolly, P., Keenan, C., and Urbanska, K. (2018). The trials of evidence-based practice in education: a systematic review of randomised controlled trials in education research 1980-2016. Educational Research, 60(3), 276-291. doi: 10.1080/00131881.2018.1493353.

Cooper, M. M. (2013). Evidence-based reform of teaching and learning. Analytical and Bioanalytical Chemistry, 406(1), 1-4. doi:10.1007/s00216-013-7438-4.

Deaton, A., and Cartwright, N. (2017). Understanding and misunderstanding randomized controlled trials. https://www. nber.org/papers/w22595. doi: 10.3386/w22595.

Haney, W. (1977, July 31). The Follow Through Planned Variation Experiment. Volume V: A Technical History of the National Follow Through Evaluation. Retrieved from https://eric. ed.gov/?id=ED152426.

Harris, A. (2019, March 11). The trump administration really wants to cut education funding. Congress doesn't. Retrieved from https://www.theatlantic.com/education/ archive/2019/03/trump-administration-would-cut-education-budget-again/584599/.

Hodges, J., McIntosh, J., and Gentry, M. (2017). The effect of an out-of-school enrichment program on the academic achievement of high-potential students from low-income families. Journal of Advanced Academics, 28(3), 204-224.

Hornbeck, B. (2017, November 3). Making good on a West Virginia promise: HSTA's success stories. Retrieved February 25, 2019 from http://www.wvexecutive.com/making-good-west-virginia-promise-hstas-success-stories/. 
Kennedy, M. M. (1978). Findings from the follow through planned variation study. Educational Researcher, 7(6), 3. doi: $10.2307 / 1175762$.

Lavrakas, P. (Ed.). Encyclopedia of survey research methods (SAGE research methods online). Thousand Oaks, Calif.: SAGE Publications, 2008.

Mann H. (1848) Report No. 12 of the Massachusetts School Board. Retrieved on February 25, 2019 from https://usa.usembassy.de/etexts/democrac/16.htm.

McKendall, S. B., Kasten, K., Hanks, S., and Chester, A. (2014). The Health Sciences and Technology Academy: An educational pipeline to address health care disparities in West Virginia. Academic Medicine: Journal of the Association of American Medical Colleges, 89(1), 37-42.

National Center for Education Statistics. Institute of Education Sciences. U.S. Department of Education. (2012) The Nation's Report Card. Science 2011 National Assessment of Educational Progress at Grade 8. Retrieved February 25, 2019 from http://nces.ed.gov/nationsreportcard /pdf/ main2011/2012465.pdf.

National Center for Education Statistics (2019), Concentration of Public School Students Eligible for Free or Reduced-Price Lunch (Last Updated: May 2019). Retrieved October 31, 2019, from https://nces.ed.gov/programs/coe/indicator clb.asp.

National Center for Public Policy Research. Civil Rights: Brown v. Board of Education I (1954). (n.d.). Retrieved from https:// nationalcenter.org/brown.html.

Pitre, C. C. and Pitre, P. (2009). Increasing underrepresented high school students' college transitions and achievements: TRIO educational opportunity programs. National Association of Secondary School Principals. NASSP Bulletin, 93(2),-96-110. Retrieved from February 22, 2019 from ProQuest. Web.

Rothstein, J. (2010). Teacher quality in educational production: Tracking, decay, and student achievement. Quarterly Journal of Economics, 125(1): 175-214.

Slavin, R. E. (2005). Evidence-Based reform: Advancing the education of students at risk. Retrieved January 2, 2019 from https://www.americanprogress.org/issues/education-k-12/ news/2005/03/01/1404/evidence-based-reform-advancing-the-education-of-students-at-risk/.

Slovacek, S., Whittinghill, J., Flenoury, L., and Wiseman, D. (2011). Promoting minority success in the sciences: The minority opportunities in research programs at CSULA. Journal of Research in Science Teaching, 49(2), 199-217.

Smith-Branch, F., McKendall S., Chester, A., Hornbeck, B., and McKendall, A. R. (2018). Demonstrating the efficacy of the Health Sciences and Technology Academy: using archival standardized test scores to analyse an OST college-preparatory program for underserved youth. The Journal of STEM Outreach, 1(1). doi: 10.15695/jstem/v1i1.19.
Steele, C. M., Spencer, S. J., and Aronson, J. (2002). Contending with group image: The Psychology of stereotype and social identity threat. Advances in Experimental Social Psychology, 34, 379-440.

U.S. Department of Education, History of the Federal TRIO Programs. (2015, November 9). Retrieved from https://www2. ed.gov/about/offices/list/ope/trio/triohistory.html.

Walpole W., McDonough P. M., Bauer C. J., Gibson C., Kanyi K., and Toliver R. (2005). THIS TEST IS UNFAIR Urban African American and Latino high school students' perceptions of standardized college admission tests. Urban Education, 40(3), 321-349 doi: 10.1177/0042085905274536.

Wandersman, A., Alia, K., Cook, B. S., Hsu, L. L., and Ramaswamy, R. (2016). Evidence-based interventions are necessary but not sufficient for achieving outcomes in each setting in a complex world: Empowerment evaluation, getting to outcomes, and demonstrating accountability. American Journal of Evaluation, 37(4), 544-561. doi:10.1177/1098214016660613.

Winkleby, M. A., Ned, J., Ahn, D., Koehler, A., Fagliano, K., and Crump, C. (2013). A controlled evaluation of a high school biomedical pipeline program: Design and methods. Journal of Science Education and Technology, 23(1), 138-144. doi: 10.1007/s10956-013-9458-4. 